THE USE OF AN AEROMEDICAL SERVICE FOR THE TRANSPORT OF PATIENTS ON INTRA-AORTIC BALLOON PUMPS IN THE REGIONALIZATION OF MEDICAL CARE

\author{
Frank J. Baker, M.D., Mary Juric, R.N., \\ Chicago, Illinois, U.S.A.
}

On 1 March 1987 the University of Chicago initiated transport of patients on intra-aortic balloon pumps using a hospital-based rotorcraft. In the subsequent eight months, 8 patients have been transported. The indications, complications, and survival of this patient group will be discussed.

The selection and training of professional staff necessary to accomplish this mission will be discussed.

\section{CRASH OF A HELICOPTER ON A HOSPITAL ROOF: PREVENTION AND DAMAGE CONTROL}

\author{
Mary Juric, R.N. and Frank J. Baker, M.D., \\ Chicago, Illinois, U.S.A.
}

On 25 April 1986, a corporate operated helicopter crashed onto the roof of the University of Chicago Hospital. The crash occurred after the helicopter had unloaded a patient and was taking off. The resultant crash was followed by a small fire and the leaking of fuel into the patient care floor immediately below the helipad.

An independent safety consultant was called in to review the safety of the aeromedical operation and to review fire procedures. Their recommendations for decreasing the chances of another crash, and for limiting damage if another crash occurs will be presented.

\section{AEROMEDICAL TRANSPORT OF THERMALLY INJURED PATIENTS}

Anne F. Missavage, M.D. and Basil A. Pruitt, Jr., M.D., Fort Sam Houston, Texas, U.S.A.

During 1986, 85 aeromedical transport operations were conducted to transfer 97 burn patients to a burn center. For 22 flights (referring hospital within 150 miles) helicopters were used and for 63 flights of greater distance ( 2 outside the United States) fixed wing aircraft were used. Two or more patients were transported on seven flights.

The flight team was dispatched from the burn center only after direct physician-to-physician communication permitted assessment of the patient's condition and coordination of treatment. The team, which always included a physician and a nurse, evaluated the patient at the referring facility and made any necessary changes in treatment prior to transport. One patient was not transported because of persistent cardiovascular instability. Insertion or change of catheters and cannulae, alteration of pulmonary support, adjustment of fluid therapy, escharotomy to improve peripheral circulation or ventilation, and pharmacologic intervention were the procedures most often needed for pre-flight stabilization and inflight management. All 97 patients accepted for transfer survived transport.

The principles that ensure the safe and efficient aeromedical transfer of burn patients and optimal flight team organization will be discussed.

\section{THE EFFECTS OF AEROMEDICAL TRANSPORT ON THE SURVIVAL OF BURN PATIENTS}

\author{
Frank J. Brown, M.D., Frank Freidman and Mary \\ Juric, R.N., Chicago, Illinois, U.S.A.
}

Between March 12, 1984 and June 15, 1986 approximately 90 patients with an initial diagnosis that included "burn" were transported by the University's aeromedical service. Of these, 71 patients are included in this study. Differences were excluded for reasons which include patients not admitted to the burn unit and patients not having true burns such as toxic epidermal necrolysis.

During the same period the total number of admissions to the burn unit was 300 while the total number of patients admitted to national burn registry hospitals was 8500 . The improved survival of the cohort transported by the aeromedical service is presented. 